\title{
Coulisses
}

Revue de théâtre

10 | Printemps 1994

Varia

\section{Quelques divagations de Jacques Livchine, imaginateur en chef pour Coulisses}

Garanties fraîches jusqu'au 18 mars 1994.

Jacques Livchine

\section{CpenEdition}

\section{Journals}

Édition électronique

URL : http://journals.openedition.org/coulisses/2851

DOI : 10.4000/coulisses.2851

ISSN : 2546-9460

\section{Éditeur}

Presses universitaires de Franche-Comté

Édition imprimée

Date de publication : 1 juin 1994

Pagination : 20-23

ISSN : $1150-594 X$

\section{Référence électronique}

Jacques Livchine, "Quelques divagations de Jacques Livchine, imaginateur en chef pour Coulisses », Coulisses [En ligne], 10 | Printemps 1994, mis en ligne le 15 mars 2019, consulté le 22 octobre 2019. URL : http://journals.openedition.org/coulisses/2851 ; DOI : 10.4000/coulisses.2851

Ce document a été généré automatiquement le 22 octobre 2019

Coulisses 


\section{Quelques divagations de Jacques Livchine, imaginateur en chef pour Coulisses}

Garanties fraîches jusqu'au 18 mars 1994.

Jacques Livchine

1 Prendre la scène Nationale de Montbéliard était pour le théâtre de l'Unité un grave défi de première importance.

2 Depuis longtemps, nos critiques étaient acerbes et enflammées contre le fonctionnement de l'Institution théatrale en France, aussi bien les Centres dramatiques, que les CAC aujourd'hui rebaptisés Scènes nationales ou les Maisons de la Culture.

\section{Nos reproches principaux :}

- Déséquilibre dans le subventionnement comparé à celui des compagnies de création. Lieux budgétivores.

- Esprit de service public peu respecté. Oubli du : «A quoi sert la subvention?».

- Primauté de l'administratif sur le vivant.

- Prise au sérieux, manque de ludisme, absence de disponibilité des directeurs.

- Absence d'utopie.

- Mépris du public-population.

- Bilans d'auto-satisfaction permanents.

- Image de marque trop élitaire.

- Incapacité à créer une atmosphère de jubilation culturelle.

- Dominance de la bien pensance et du pas-de-vagues, frilosité, soumission aux municipalités.

- Perte du sentiment festif originel du théâtre.

- Conformisme, tendance à faire partie d'une chaîne.

- Relation au public principalement basée sur des réductions commerciales. 
C'était donc un réquisitoire en treize points, bien sûr, on ne peut pas dire qu'un seul lieu cumulait les treize points négatifs, mais chacun était atteint au moins par trois de ces maladies. Or, nous voilà à notre tour à la Direction d'un établissement culturel de ce type : Allons-nous être différents? En sommes-nous capables?

\section{Que voulions-nous prouver?}

\section{Comment quitter Paris pour Montbéliard?} urbain accentué, pour qu'au moins l'enjeu soit un parcours d'obstacles difficiles.

11 Montbéliard correspondait parfaitement à ces définitions. Dominée par la monoindustrie, la vie y est difficile. La Ville a du mal à s'assumer entre son luthérianisme de base, une importante immigration, des difficultés économiques, les jeunes qui étudient ailleurs, les militants politiques et syndicaux de gauche très malmenés par la direction de la " grande maison», etc.

12 Il nous est arrivé parfois de qualifier Montbéliard de ville « autiste » et le 20 septembre nous avons inauguré notre Scène Nationale, baptisée: "Centre d'Art et de Plaisanterie » en hommage à Dubuffet.

13 Le titre n'a pas trop plu aux autorités de tutelle qui associent et acceptent trop naturellement les trois vocables « culture, sérieux, ennui ».

14 «Plaisanterie » est dure à porter pour tous les infatués incontournables des Ministères et tous les Gardiens de la culture comme activité « élitaire ».

\section{« Regarder la vie en farce»}


«Il ne s'agit pas de remplir le théâtre de Montbéliard, mais de remplir Montbéliard de théâtre. "

Comme tout ce qui est nouveau, notre aventure Montbéliardaise a commencé par un rejet d'une partie de la population, appelons-la « l'élite cultivée », qui a la prétention de s'y connaître et qui a senti qu'on leur arrachait leurs privilèges, car le drame est là :

18 L'argent de la subvention sert avant tout à aider et à favoriser la venue au spectacle d'un public qui la plupart du temps est déjà totalement privilégié socialement.

Disons que le public qui fréquente les théâtres a largement, question de salaire, le double du SMIC, et question diplôme on est toujours largement au-dessus du baccalauréat.

Les exceptions sont rares et ne sont dues qu'à un travail militant forcené. Quelques CE, et les scolaires qui malheureusement trop souvent, mal préparés, ou entraînés malgré eux, peuvent nuire à la qualité d'écoute du spectacle.

La plupart des spectacles présentés dans le circuit "Scène Nationale » implique un certain nombre de codes, de repères, de connaissances préalables.

Notre Centre d'Art et de Plaisanterie est en train d'avancer très doucement sur de nouveaux chemins, certains étaient parcourus il y a quelques années et ont été abandonnés, d'autres sont liés à notre personnalité et à l'Eros qui nous habite en permanence.

\section{Nous refusons le rôle de simple vendeur de billets de théâtre}

21 Nous ne sommes pas un centre de grande consommation culturelle, ni un supermarché de la culture comme on disait en 1968.

Pourtant dans les comptes qui nous sont réclamés, ce sont tous les chiffres de fréquentation qui doivent figurer en priorité ainsi que la part des recettes propres dans notre budget.

Bien sûr, certaines statistiques montrent que parfois les Scènes Nationales multiplient des choix pointus sans parvenir à rassembler un public suffisant. Il est fréquent de voir des salles de 80 payants pour des spectacles dont le coût de la venue peut être de 100000 francs, soit une place qui coûte au contribuable environ 1200 francs, ce qui est immoral, mais qui peut arriver lorsqu'un choix qui paraît évident n'est pas du tout partagé par le public.

A Montbéliard nous avons été très ébranlés par la non réponse du public à certains de nos choix musicaux : Bernard Lubat, Roulez fillettes, mais aussi par certaines valeurs qui nous paraissaient indéniables comme Philippe Caubère par exemple.

Mais on sait aussi qu'un grand nombre d'abonnés n'est pas forcément la marque d'une grande politique inventive.

Il suffit pour le professionnel de la programmation de travailler avec quatre ou cinq agents qui proposent des produits " porteurs ", variétés ou vedettes, et le résultat sera indéniablement bon sur le plan quantitatif.

Donc nous ne classons ni comme vendeur de billets, ni comme programmateur. 


\section{L'Hôtel de Sponeck, le dernier abri} Les artistes se sont mis à s'adresser surtout à leurs pairs, financeurs ou amis, l'Art ne
bouleverse plus l'ordre social, c'est un agréable divertissement qui se joue entre la page bouleverse plus l'ordre social, c'est un agréable divertissement qui se joue entre la page
culturelle du quotidien National le plus coté, trois directeurs de théâtre, deux inspecteurs du Ministère et trois professionnels.

Là-dessus se rajoute un public en état de léthargie totale, il a acheté son abonnementsigne-de-standing-social en début d'année, le théâtre n'a pour lui aucune fonction spirituelle, mais une fonction sociale. Sortir au théâtre, c'est assez « classe ». La conversation s'arrête d'ailleurs sur les marches du théâtre : on a aimé ou on n'a pas aimé.

C'est donc la bataille du C.A.P. aujourd'hui.

Nous avons inventé les "Samedis piétons", le «Réveillon des boulons", des " vernissages fêtes ", et mille et une action pour sortir du ron ron.

C'est long, on ne peut pas non plus être des transformateurs sociaux, les murs ne sont plus à Berlin, soit, mais ils continuent d'être à l'intérieur de chaque être social, le jeu c'est de les fissurer et de les casser.

$$
\begin{aligned}
& \text { Il est évident que si la culture reste } \\
& \text { en rond. La consanguinité est une des } \\
& \text { Les artistes se sont mis à s'adresser } \\
& \text { bouleverse plus l'ordre social, c'est } \\
& \text { culturelle du quotidien National } \\
& \text { inspecteurs du Ministère et trois prof } \\
& \text { Là-dessus se rajoute un public en ét } \\
& \text { signe-de-standing-social en début } \\
& \text { spirituelle, mais une fonction sociale. } \\
& \text { Sortir au théâtre, c'est assez « classe } \\
& \text { La conversation s'arrête d'ailleurs s } \\
& \text { aimé. } \\
& \text { C'est donc la bataille du C.A.P. aujourd' } \\
& \text { Nous avons inventé les "Samedis } \\
& \text { vernissages fêtes ", et mille et une } \\
& \text { C'est long, on ne peut pas non plus } \\
& \text { plus à Berlin, soit, mais ils continuent } \\
& \text { c'est de les fissurer et de les casser. } \\
& \text { Coulisses, 10 | Printemps 1994 }
\end{aligned}
$$


5 Sponecks

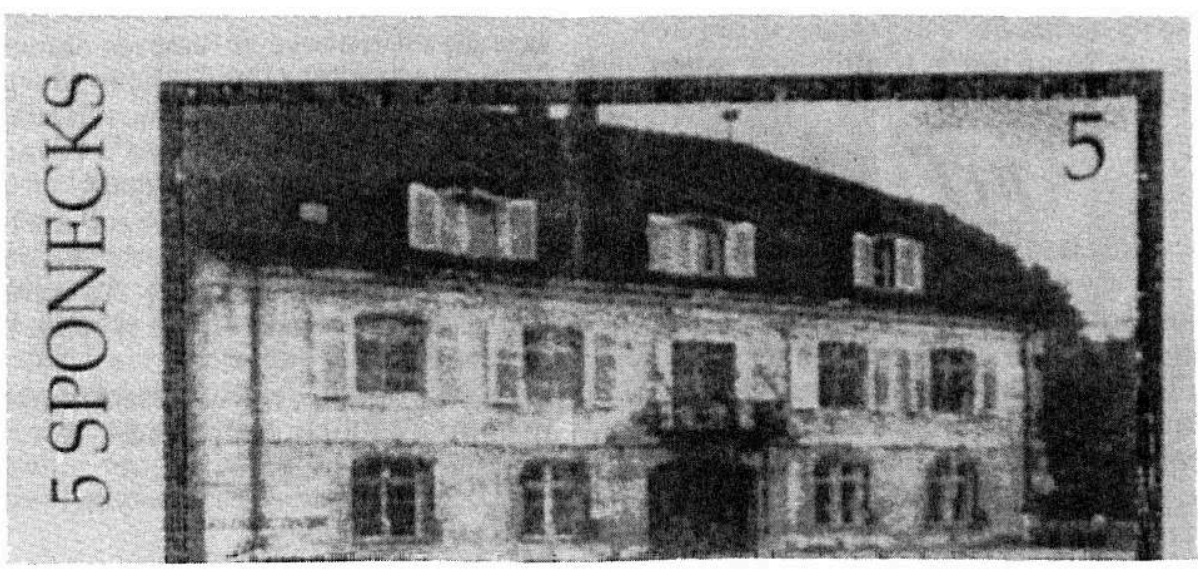

